\title{
Two manual therapy techniques for management of lumbar radiculopathy: a randomized clinical trial
}

https://doi.org/10.1515/jom-2020-0261

Received October 5, 2020; accepted December 10, 2020; published online February 26, 2021

\section{Abstract}

Context: Evidence has shown that spinal mobilization with leg movement (SMWLM) and progressive inhibition of neuromuscular structures (PINS) are individually effective in the management of lumbar radiculopathy. However, previous evidence reported data for only a short-term study period and did not investigate the effect of the combined manual therapy techniques.

Objectives: To compare the combined effects of two manual therapy techniques (SMWLM and PINS) with the individual techniques alone (SMWLM or PINS) in the management of individuals with lumbar radiculopathy.

Methods: A total of 60 patients diagnosed with unilateral lumbar radiculopathy secondary to disc herniation were randomly allocated into three groups: 20 participants each in the SMWLM, PINS, and combined SMWLM + PINS groups. Each group attended two treatments per week for 30 min each, for three months. Participants were assessed at baseline, immediately posttreatment, and then at three, six, and nine months follow-up using the Visual Analog Scale (VAS), Rolland-Morris Disability Questionnaire (RMDQ), and Sciatica Bothersomeness Index (SBI).

Results: Between-groups analyses using a two-way repeated-measures analysis of variance indicated significant interactions between groups and follow-up times for

\footnotetext{
*Corresponding author: Musa S. Danazumi, PT, MSc, Department of Physiotherapy, Federal Medical Center, Nguru, 630101, Yobe State, Nigeria, E-mail: musadanazumisani@gmail.com

Bashir Bello, PT, PhD and Bashir Kaka, PT, PhD, Department of Physiotherapy, Faculty of Allied Health Sciences, College of Health Sciences, Bayero University, Kano, Nigeria

Abdulsalam M. Yakasai, PT, PhD, Medical Rehabilitation Therapists (Reg.) Board of Nigeria, North-West Zonal Office, Kano, Nigeria; and Department of Physiotherapy, College of Health Sciences, University of KwaZulu-Natal, Durban, South Africa
}

all outcomes $(\mathrm{p}=0.001)$. Participants receiving combined SMWLM + PINS treatment experienced greater improvement in leg pain, back pain, disability, and sciatica at all timelines (immediately posttreatment, and three, six, and nine months follow-up) than the participants receiving SMWLM or PINS alone $(\mathrm{p}<0.05)$. However, participants receiving SMWLM alone showed better improvement than the participants receiving PINS alone at all timelines $(\mathrm{p}<0.05)$.

Conclusions: A combined SMWLM + PINS treatment protocol showed greater improvement than the individual techniques alone in the management of individuals with LR in this study.

Keywords: lumbar disc herniation; lumbar radiculopathy; neuromuscular inhibition; spinal mobilization.

Lumbar radiculopathy is characterized by radiating pain in an area of the leg typically served by one lumbar or sacral spinal nerve root in combination with dermatomal and/or tendon reflex abnormalities [1]. The problem is commonly caused by degenerative conditions, such as a herniated nucleus pulposus or lumbar spinal stenosis, and occurs in approximately $3-5 \%$ of the population, with about $10-25 \%$ of those affected having a recurrence of symptoms that usually persist for more than three months [2].

Studies have indicated that conservative management of lumbar radiculopathy should be attempted in the absence of worsening neurological signs or cauda equina syndrome before surgical interventions [3, 4]. Based on this, many forms of conservative care, including manual therapy, have been developed and investigated in the management of this condition [5-7]. Moreover, evidence from international guidelines [8-10] and systematic reviews [11-13] indicate that manual therapy techniques are effective for both short and long-term pain and disability management in patients with back-related lower extremity symptoms. Despite this, there are no standardized 
guidelines for appropriate manual therapy techniques comprising the most effective interventions for individuals with lumbar radiculopathy, suggesting that more treatment options are needed [8-17].

A previous study [18] investigated the effect of two manual therapy techniques, spinal mobilization with leg movement (SMWLM) and progressive inhibition of neuromuscular structures (PINS), in the management of lumbar radiculopathy; results showed that both SMWLM and PINS were individually effective on pain, disability, and sciatica, but no significant differences were observed between the two manual therapy techniques postintervention. That study [18] reported data for a short-term period (eight weeks postintervention) and did not investigate combined manual therapy techniques. Given that SMWLM has been hypothesized to relieve nerve compression [19] and PINS has been hypothesized to normalize reflex activity in the neuromuscular structures [20], we hypothesized that a combination of the two techniques could produce a better outcome than the individual techniques alone. Accordingly, this study was conducted to examine the combined effect of SMWLM and PINS in the management of individuals with lumbar radiculopathy secondary to disc herniation.

\section{Methods}

\section{Research design and ethics}

This was a single-blind, parallel, randomized, clinical trial; the research participants were blinded to randomization. Because of the nature of the study, investigators were not blinded, but outcomes assessors and data analysts were blinded. Ethical approval to conduct this study was obtained from the Health Research Ethics Committee of the Federal Medical Centre (FMC), Nguru, Yobe State, Nigeria (Registration number: FMC/N/CL.SERV/355/VOL.IV/139). Written informed consent was obtained from the participants, they were assured of their rights to withdraw from the study at any point in time, and their full anonymity was maintained. The trial was registered with the Pan African Clinical Trial Registry (PACTR201907782710996) on July 11, 2019. The study was begun on July 15, 2019 and ended on September 11, 2020.

\section{Sample size estimation}

The sample size was calculated using the $G^{\star}$ Power version 3.1 software [21]. The effect size used for calculating the sample size was obtained from previous research by Das et al. [22] using disability as the primary outcome. The probability level $(\alpha)$, the power $(p)$, the effect size (ES), the number of groups, the number of measurements, and correlation among repeated measures used for the calculation were set at 0.05 , $0.8,0.38,3,6$, and 0.5 , respectively, which yielded a total sample size of 45 participants (15 per group), using repeated measures (between factors) analysis of variance (ANOVA). According to a previous study [23], a 20\% attrition rate should be accounted for a clinical trial of equal allocation to groups, so our the sample size was adjusted to 60 participants (20 per group) to anticipate this potential loss due to attrition.

\section{Eligibility criteria}

Participants diagnosed as having a chronic (lasting three months or longer) [2-4] lumbar radiculopathy secondary to L4/L5 and L5/S1 lumbar disc herniation (confirmed on magnetic resonance imaging) were included in the study. Patients with chronic lumbar radiculopathy were selected because of the prior evidence that acute cases may resolve spontaneously within a few weeks of onset [2-4]. Adults with an age range of 18-65 years having unilateral radiculopathy and pain in the distribution of sciatic nerve (leg-dominant symptoms) were included. Pain was accepted as evidence of L5/L4 root compression when distributed to the anterolateral aspect of the leg and the dorsum of the foot, and as evidence of $\mathrm{L} 5 / \mathrm{S} 1$ root compression when distributed to the posterior aspect of the leg extending to the heel and lateral aspect of the foot. Radiating pain was evoked by specific clinical tests, including slump, straight leg raising [24-26], and Lasègue's sign [27]. The exclusion criteria were: diagnosis of lumbar disc herniation with bilateral radiculopathy, diagnosis of other back conditions (e.g., failed back syndrome, spondylolysis/spondylolisthesis, spinal stenosis, mechanical low back pain or neoplasmic and infectious processes), and participants currently receiving treatments. Participants with severe nerve root compression (non-ambulant/wheelchair-bound) or having cauda equine syndrome were also excluded because it was believed that these participants might better benefit from surgery [28].

\section{Data collection procedure}

Participant recruitment: Participants were referred from the general outpatient department (GOPD) and surgical outpatient department (SOPD) to the department of physiotherapy where the study was conducted. Participants were verbally invited to participate in the study and then screened for eligibility by a trained orthopedic physiotherapist (M.S.D.). Participants who met the eligibility criteria and were willing to participate were recruited, and written informed consents were obtained. Participants were recruited consecutively throughout the study period until the sample size needed was achieved.

Outcomes assessment: Outcomes were assessed at baseline and posttreatment (after three months of intervention). Treatment ended after three months of intervention and then patients were given lumbar stabilization and stretching exercises [18] as a home regimen. Outcomes were further assessed through physical visits and phone calls at three, six, and nine months of follow-up.

(1) Visual Analog Scale (VAS): This scale was used to measure leg and back pain intensities experienced by the participants. The assessment was based on a horizontal $10 \mathrm{~cm}$ scale varying from 0 (no pain in the leg) to $10 \mathrm{~cm}$ (the worst pains ever). VAS has been shown to have high interobserver reliability coefficient $(\mathrm{r}=0.88)$ and a $30 \%$ change is considered clinically significant [29].

(2) Roland Morris Disability Questionnaire (RMDQ): This questionnaire was used to measure functional limitation among participants. Scores range from 0 to 24 , with higher scores reflecting more severe 
disability. The RMDQ has been shown to have a high level of internal consistency reliability (Cronbach's alpha of 0.87 ), and testretest reliability (ICC of 0.9$) ; 2-3(8-12 \%)$ point change is considered clinically significant [29].

(3) Sciatica Bothersomeness Index (SBI): This scale was used to assess the level of sciatica among participants. The scale's scores range from 0 to 24, with higher scores reflecting more severe sciatica bothersomeness. This scale has a high level of internal consistency reliability (Cronbach's alpha of 0.70 ) and test-retest reliability (ICC of 0.90); a change of 6.5 points is considered clinically significant [30].

Randomization of participants: Eligible participants who provided informed consent were randomized into one of three treatment groups: SMWLM, PINS, or combined SMWLM + PINS. A randomization timeline was prepared by a research assistant who had no communication with the participants throughout the trial and was unaware of the study protocol. The randomization series (using block randomization) was created using SAS 9.4 statistical software with the participants likely to be assigned to a group with an equal chance of allocation (Figure 1).

Intervention procedure: There were three intervention groups in this study, with the first group receiving SMWLM, the second group receiving PINS, and the third group receiving combined SMWLM + PINS treatment techniques. Treatments sessions for both the single and combined treatment groups were carried out on the same day. However, participants in the single treatment groups spent additional time receiving lectures on lumbar spine anatomy, to compensate for not receiving dual therapies. Each group (both single and combined) attended two treatments per week of for $30 \mathrm{~min}$ each, for three months. Additionally, each group also received neural tissue mobilization [31] as a baseline treatment.

SMWLM technique: Participants in the SMWLM group received SMWLM as per Mulligan's guidelines [32]. The participant was laid on the side, facing the treating physiotherapist (PT; M.S.D.), with the leg to be treated on top. An assistant PT supported the uppermost leg. The treating PT then bent over the participant and put one thumb, supported by the other, on the spinous process of the affected vertebra as determined with reference to the posterior superior iliac crest. The treating PT then pressed down on the palpated spinous process. This pressure was maintained while the participant actively performed the straight leg raise (SLR) for the leg supported by the assistant PT, in as much as this did not cause pain. This position was retained for $30 \mathrm{~s}$, after which the treating PT released the pressure on the spinous process and the participant lowered the supported leg to the treatment table. Three repetitions were applied during the first visit. However, as the participant improved in subsequent visits, the assistant PT applied overpressure on the supported leg as the participant performed the SLR. This was also maintained for $30 \mathrm{~s}$, after which the leg was lowered to the treatment table (Figure 2). This procedure was repeated six times on subsequent visits.

PINS technique: Participants in the PINS group received the PINS program as per Dowling's guidelines [20]. Two connected points, named primary and endpoints, were palpated using the index fingers of both hands. The points were areas of most and least sensitivity, respectively, found along a neuromuscular structure. When an area of least sensitivity (endpoint) was found, a moderate ischemic compression was applied with the index finger of one hand without relieving the pressure until the treatment is complete. When an area of most sensitivity was found (primary point), a moderate ischemic compression was also applied with the index finger of the other hand for $30 \mathrm{~s}$, after which another sensitive point was identified with the middle finger of the same hand proximal to the endpoint without relieving the pressure of the index finger. When the pressure on the middle finger was noted as more sensitive than on the index finger, then the index finger pressure was relieved and that of the middle finger was maintained without relieving the endpoint pressure. This was maintained for $30 \mathrm{~s}$ before the third point was identified. Similar patterns for all identified sensitive points were followed continuously along the neuromuscular continuum until the last point, approximately $2 \mathrm{~cm}$ proximal to the endpoint, was found. The pressure was maintained for $30 \mathrm{~s}$ concurrently on the two points (the last and the endpoint) and then relieved (Figure 3).

Compliance with home program: Therapeutic exercises (lumbar stabilization and stretching exercises) were initiated at low speed (beginner stage) during the treatment sessions to ensure that each participant received appropriate exercise instructions and progression modes before discharge. After treatment ended, participants were given a handout detailing appropriate exercise dosages and progressions. We provided the same exercise guidelines reported in our previous study [18]. Additionally, exercise compliance was assessed and reinforced every four weeks via phone calls and every 3 months at in-person visits. Further, participants were also asked to refrain from all other rehabilitation techniques or exercise not prescribed by the trial physiotherapists; this was also monitored periodically via phone calls and physical visits.

Statistical analysis: All data were analyzed using SPSS 23.0 (SPSS, Inc.). Descriptive statistics were used to summarize the demographics and clinical parameters of the participants. Shapiro-Wilk test was used to assess the normality of the data, while Levene's test was used to assess the homogeneity of variances among groups. One-way ANOVA was used to compare outcomes at baseline. The primary aim of the study (effects of interventions on pain, disability, and sciatica) was examined by the use of two-way repeated-measures ANOVA with the intervention group (SMWLM, PINS, and combined SMWLM + PINS) as the between-subject variable and time (baseline, posttreatment, and three, six, and nine months follow-up) as the within-subject variable. Separate ANOVAs were performed with the outcomes (back pain, leg pain, disability, and sciatica) as the dependent variables and for each ANOVA, the analysis of interest was the two-way interaction (Group $\times$ Time). The data of the participants lost to follow-up were treated by intention-to-treat analysis (ITT) by removing the lost data in the analysis (on protocol/per protocol/ completer analysis procedure) [33]. Differences between the means were considered at $5 \%$ probability level $(\mathrm{p}<0.05)$ and the value of confidence interval (CI) was set at $95 \%$.

\section{Results}

A total of 60 participants (age range, 36-59 years; mean age, $47.8 \pm 4.32$ years) were enrolled in the study, with 20 


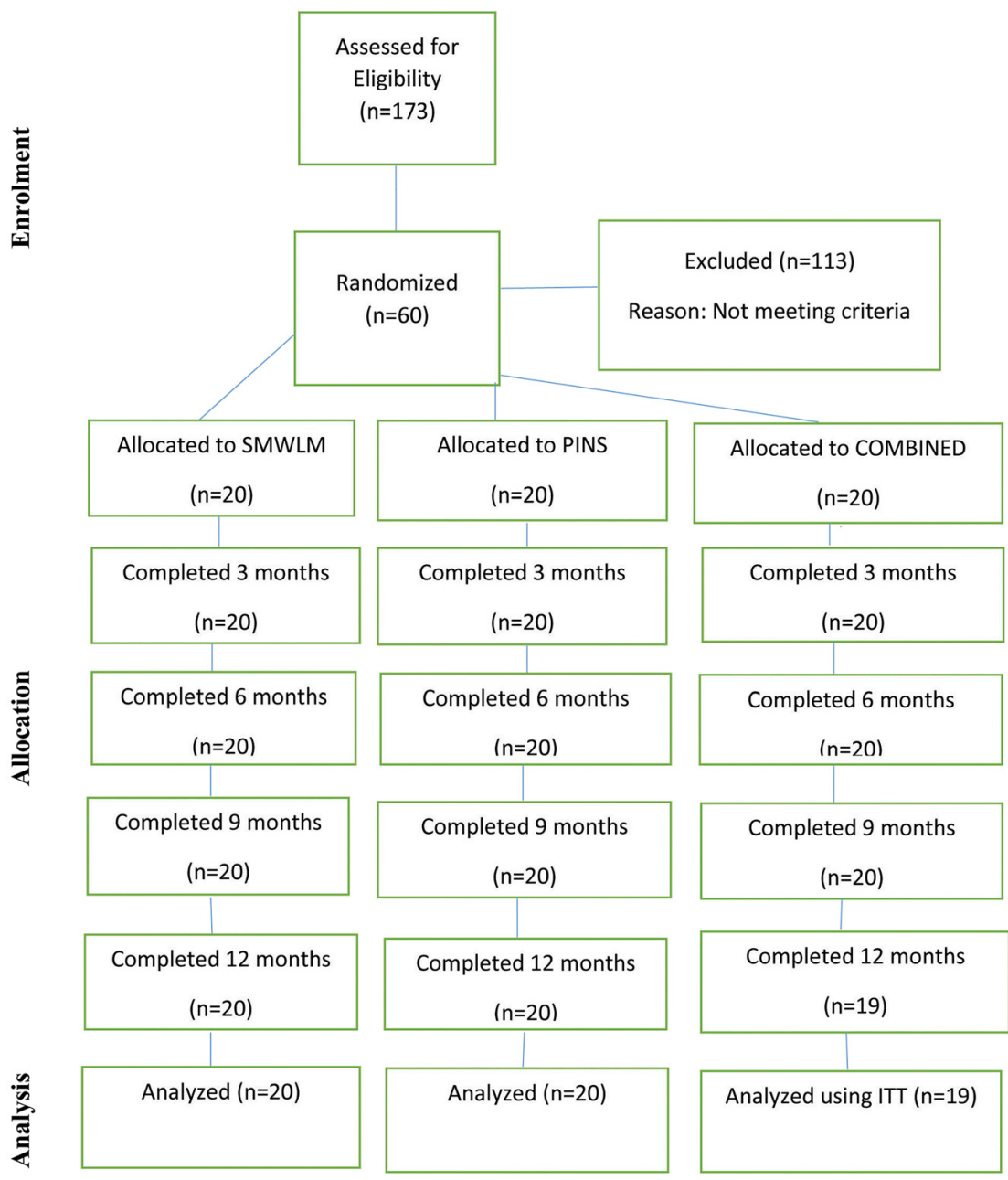

Figure 1: Chart demonstrating the flow of patients through this randomized clinical study.

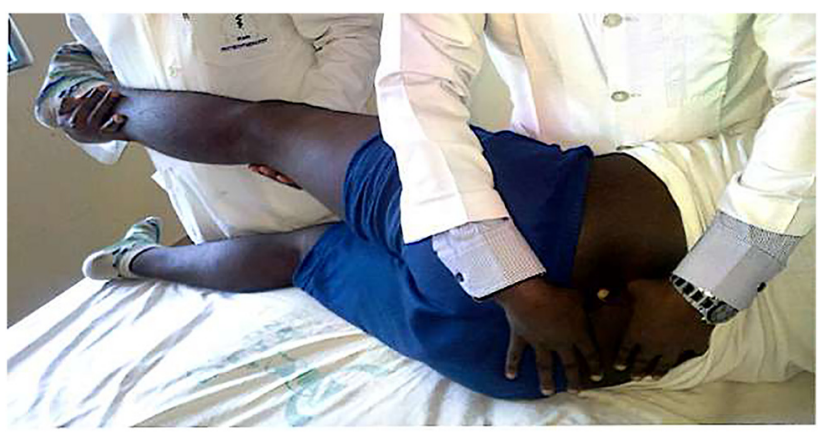

Figure 2: Spinal mobilization with leg movement. The patient is lying on the side with the affected lower limb uppermost, and the treating physiotherapist (PT) is facing and stooping over the patient. The treating PT pushes down the chosen spinous process using reinforced thumbs and the assistant PT supports the uppermost leg of the patient when straight leg raising is performed. participants each in the SMWLM, PINS, and combined SMWLM + PINS treatment groups. Thirty-seven (61.7\%) participants were men and $23(38.3 \%)$ participants were women. One participant in the SMWLM + PINS treatment group was lost at the nine-month follow-up period and his data was adjusted through intention-to-treat (ITT) analysis by removing the nine-month follow-up data from the analysis. No significant differences were observed in the baseline characteristics of the study participants among groups (Table 1).

Between-groups analyses using a two-way repeatedmeasures ANOVA indicated significant interactions between group and time (Group $\times$ Time) for all outcomes: $\operatorname{RMDQ}[F(4,116)=15.994 ; \mathrm{p}=0.001)]$, VAS in the leg $[F(4,116)$ $=14.10,7 ; \mathrm{p}=0.001)]$, VAS in the back $[F(4,116)=7.469$, $\mathrm{p}=0.001)]$, SBI $[F(4,116)=8.073 ; \mathrm{p}=0.001)]$ (Table 2). 


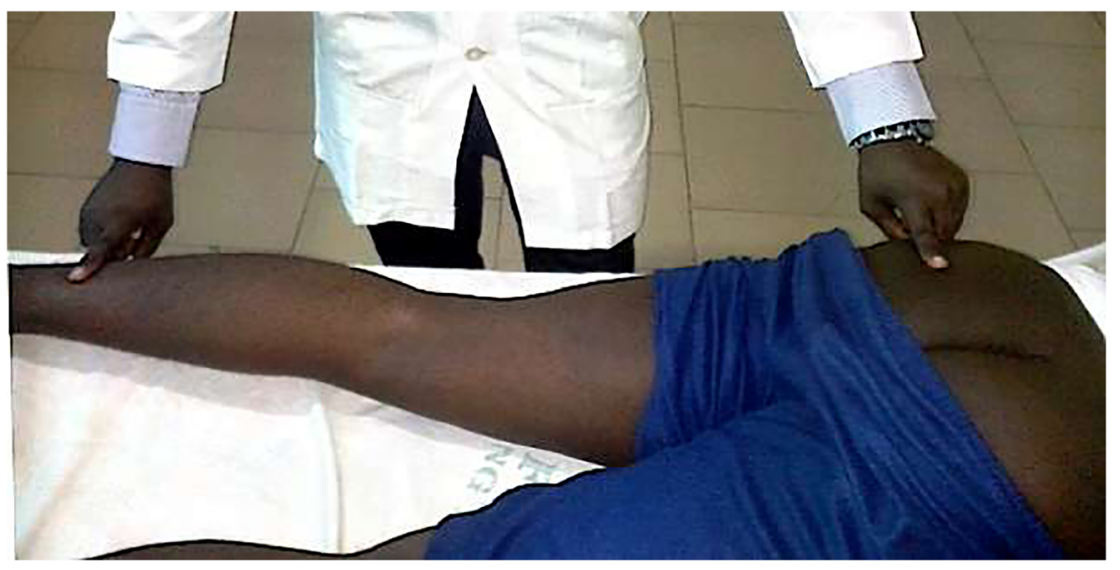

Figure 3: Progressive inhibition of neuromuscular structures. The patient is lying prone and the treating physiotherapist (PT) is standing at the same side with the patient's ipsilateral lower limb. The treating PT's proximal index finger is placed at the primary end point and the distal index finger is placed at the secondary end point. The proximal finger of the PT applies ischemic compression at primary end points, moving progressively towards the distal index finger to approximately the $2 \mathrm{~cm}$ mark, and then both pressures are relieved at once.

Post-hoc analyses (of Group $\times$ Time effects) indicated that participants who received combined SMWLM + PINS)= treatment experienced greater improvement in leg pain $(\mathrm{p}<0.05)$, back pain $(\mathrm{p}<0.05)$, disability $(\mathrm{p}<0.05)$ and sciatica bothersomeness $(\mathrm{p}<0.05)$, immediately posttreatment (Table 3), and at three-month (Table 4), six-month (Table 5), and nine-month (Table 6) follow-up periods than the participants receiving SMWLM or PINS alone. However, participants receiving SMWLM showed better improvement than the participants receiving PINS at all timelines (Tables 3-6).

\section{Discussion}

This study investigated the combined effects of SMWLM and PINS compared with the individual techniques alone in the management of individuals with lumbar

Table 1: Baseline demographics and clinical characteristics.

\begin{tabular}{lrrrr}
\hline Variable & $\begin{array}{r}\text { SMWLM } \\
\text { Mean (SD) } \\
(\mathbf{n = 2 0 )}\end{array}$ & $\begin{array}{r}\text { Mean (SD) } \\
(\mathbf{n = 2 0 )}\end{array}$ & $\begin{array}{r}\text { Combined } \\
\text { Mean (SD) } \\
(\mathbf{n = 2 0 )}\end{array}$ & p-value \\
\hline Age, years & $45.44(8.84)$ & $49.51(10.06)$ & $47.33(12.09)$ & 0.176 \\
BMI, kg/m ${ }^{2}$ & $24.59(1.83)$ & $25.35(2.52)$ & $26.73(2.86)$ & 0.682 \\
DOS, months & $8.95(1.07)$ & $9.10(0.97)$ & $9.05(1.02)$ & 0.981 \\
RMDQ & $13.40(3.83)$ & $13.25(3.14)$ & $14.13(3.40)$ & 0.114 \\
VASL & $8.75(2.05)$ & $7.50(2.04)$ & $7.26(2.02)$ & 0.825 \\
VASB & $4.67(3.21)$ & $4.81(2.73)$ & $4.94(2.56)$ & 0.089 \\
SBI & $16.35(4.30)$ & $15.35(4.30)$ & $17.51(4.76)$ & 0.813 \\
\hline
\end{tabular}

BMI, body mass index; DOS, duration of symptoms; PINS, progressive inhibition of neuromuscular structures; RMDQ, Rolland-Morris disability questionnaire; SBI, sciatica bothersome index; SD, standard deviation; SMWLM, spinal mobilization with leg movement; VASL, Visual Analog Scale for leg pain; VASB, Visual Analog Scale for back pain. radiculopathy secondary to disc herniation. The findings of this study showed that there were significant within-group differences for all outcomes at all timelines (immediately posttreatment and three, six, and nine months follow-up periods), indicating that all measures significantly improved over time from baseline to 12 months. This finding is congruent with those of a previous study [18], in which a significant improvement in all outcomes at all timelines was reported. Similar findings were also reported in other previous studies $[22,31,34,35]$ that examined the effect of SMWLM compared with other interventions. However, in contrast with a previous study [18] and other studies [22, 34, 35], ours examined the combined effects of

Table 2: Two-way repeated measures ANOVA for between group and time interactions.

\begin{tabular}{lrr}
\hline Variable & $\boldsymbol{F}(\boldsymbol{d f})$ & p-value \\
\hline RMDQ & $202.071(2,58)$ & \\
Group & $25.322(2,116)$ & $<0.001$ \\
Time & $15.994(4,116)$ & $<0.001$ \\
Group $\times$ Time & $139.673(2,58)$ & $<0.001$ \\
VASL & $9.901(2,116)$ & $<0.001$ \\
Group & $14.107(4,116)$ & $<0.001$ \\
Time & & $<0.001$ \\
Group $\times$ Time & $121.303(2,58)$ & \\
VASB & $15.645(2,116)$ & $<0.001$ \\
Group & $7.469(4,116)$ & $<0.001$ \\
Time & & $<0.001$ \\
Group $\times$ Time & $89.966(2,58)$ & $<0.001$ \\
SBI & $13.178(2,116)$ & $<0.001$ \\
Group & $8.073(4,116)$ & $<0.001$ \\
Time &
\end{tabular}

RMDQ, Rolland-Morris Disability Questionnaire; SBI, sciatica bothersome index; VASL, Visual Analog Scale for leg pain; VASB, Visual Analog Scale for back pain. 
Table 3: Baseline to posttreatment change scores for clinical outcomes.

\begin{tabular}{|c|c|c|c|c|c|c|}
\hline Variable & Group (n) & $\begin{array}{r}\text { Baseline } \\
\text { Mean (SD) }\end{array}$ & $\begin{array}{r}\text { Posttreatment } \\
\text { Mean (SD) }\end{array}$ & $\begin{array}{r}\text { Within-group } \\
\text { change score } \\
\text { Mean (SD) }\end{array}$ & $\begin{array}{r}\text { Between-group change score } \\
\text { Mean }(95 \% \mathrm{Cl})\end{array}$ & p-value \\
\hline \multirow[t]{3}{*}{ RMDQ } & SMWLM (20) & $13.40(3.83)$ & $11.04(3.14)$ & $2.36(4.61)$ & $5.03(2.41-5.81)$ & 0.001 \\
\hline & PINS (20) & $13.25(3.14)$ & $11.23(4.81)$ & $2.02(5.30)$ & & \\
\hline & COMBINED (20) & $14.13(3.40)$ & $9.11(3.12)$ & $5.11(3.64)$ & & \\
\hline \multirow[t]{3}{*}{ VASL } & SMWLM (20) & $8.75(2.05)$ & $5.62(1.23)$ & $3.14(2.12)$ & $3.48(1.82-3.47)$ & 0.001 \\
\hline & PINS (20) & $7.50(2.04)$ & $5.21(1.03)$ & $2.28(3.36)$ & & \\
\hline & COMBINED (20) & $7.26(2.02)$ & $4.01(1.61)$ & $3.25(2.97)$ & & \\
\hline \multirow[t]{3}{*}{ VASB } & SMWLM (20) & $4.67(3.21)$ & $3.21(1.98)$ & $1.46(1.32)$ & $2.88(0.96-3.02)$ & 0.034 \\
\hline & PINS (20) & $4.81(2.73)$ & $4.02(2.54)$ & $0.81(2.71)$ & & \\
\hline & COMBINED (20) & $4.94(2.56)$ & $3.05(1.36)$ & $1.89(0.65)$ & & \\
\hline \multirow[t]{3}{*}{ SBI } & SMWLM (20) & $16.35(4.30)$ & $12.32(5.11)$ & $4.02(4.31)$ & $4.62(3.96-7.21)$ & 0.020 \\
\hline & PINS (20) & $15.35(4.30)$ & 13.01 (4.69) & $2.34(6.03)$ & & \\
\hline & COMBINED (20) & $17.51(4.76)$ & $11.97(5.48)$ & $5.56(4.61)$ & & \\
\hline
\end{tabular}

$\mathrm{Cl}$, confidence interval; RMDQ, Rolland-Morris Disability Questionnaire; SBI, Sciatica Bothersome Index; SD, standard deviation; VASL, Visual Analog Scale for leg pain; VASB, Visual Analog Scale for back pain.

Table 4: Posttreatment to three-month follow-up change scores for clinical outcomes.

\begin{tabular}{|c|c|c|c|c|c|c|}
\hline Variable & Group (n) & $\begin{array}{r}\text { Immediate } \\
\text { posttreatment } \\
\text { Mean (SD) }\end{array}$ & $\begin{array}{r}\text { Three-month } \\
\text { follow-up } \\
\text { Mean (SD) }\end{array}$ & $\begin{array}{r}\text { Within-group } \\
\text { change score } \\
\text { Mean (SD) }\end{array}$ & $\begin{array}{r}\text { Between-group change } \\
\text { score mean }(95 \% \mathrm{Cl})\end{array}$ & p-value \\
\hline \multirow[t]{3}{*}{ RMDQ } & SMWLM (20) & $11.04(3,14)$ & $8.13(4.38)$ & $2.92(6.27)$ & $4.97(1.24-5.03)$ & 0.001 \\
\hline & PINS (20) & $11.23(4.81)$ & $8.04(3.98)$ & $3.18(5.01)$ & & \\
\hline & COMBINED (20) & $9.11(3.12)$ & $5.87(5.16)$ & $3.26(4.88)$ & & \\
\hline \multirow[t]{3}{*}{ VAS } & SMWLM (20) & $5.62(1.23)$ & $4.02(2.43)$ & $1.62(3.33)$ & $2.43(1.10-3.31)$ & 0.042 \\
\hline & PINS (20) & $5.21(1.03)$ & $4.01(1.89)$ & $1.18(2.45)$ & & \\
\hline & COMBINED (20) & $4.01(1.61)$ & $2.68(3.01)$ & $1.35(1.68)$ & & \\
\hline \multirow[t]{3}{*}{ VASB } & SMWLM (20) & 3.21 (1.98) & $2.98(3.71)$ & $0.25(1.00)$ & $1.67(1.13-1.88)$ & 0.022 \\
\hline & PINS (20) & $4.02(2.54)$ & $3.97(2.62)$ & $0.05(2.33)$ & & \\
\hline & COMBINED (20) & $3.05(1.36)$ & $2.21(2.53)$ & $0.84(1.96)$ & & \\
\hline \multirow[t]{3}{*}{ SBI } & SMWLM (20) & $12.32(5.11)$ & $8.82(6.21)$ & $3.50(2.19)$ & $2.60(1.88-6.27)$ & 0.012 \\
\hline & PINS (20) & $13.01(4.69)$ & $11.01(8.87)$ & $2.01(4.52)$ & & \\
\hline & COMBINED (20) & $11.97(5.48)$ & $7.12(4.69)$ & $4.85(3.83)$ & & \\
\hline
\end{tabular}

RMDQ, Rolland-Morris Disability Questionnaire; SBI, Sciatica Bothersome Index; VASL, Visual Analog Scale for leg pain; VASB, Visual Analog Scale for back pain.

Table 5: Three-month to six-month follow-up change scores for clinical outcomes.

\begin{tabular}{|c|c|c|c|c|c|c|}
\hline Variable & Group (n) & $\begin{array}{r}\text { Three-month } \\
\text { follow-up } \\
\text { Mean (SD) }\end{array}$ & $\begin{array}{r}\text { Six-month } \\
\text { follow-up } \\
\text { Mean (SD) }\end{array}$ & $\begin{array}{r}\text { Within-group } \\
\text { change score } \\
\text { Mean (SD) }\end{array}$ & $\begin{array}{r}\text { Between-group change } \\
\text { score mean }(95 \% \mathrm{Cl})\end{array}$ & p-value \\
\hline \multirow[t]{3}{*}{ RMDQ } & SMWLM (20) & $8.13(4.38)$ & $5.33(2.71)$ & $2.78(1.21)$ & $3.03(2.14-4.01)$ & 0.001 \\
\hline & PINS (20) & $8.04(3.98)$ & $6.00(4.01)$ & $2.04(2.67)$ & & \\
\hline & COMBINED (20) & $5.87(5.16)$ & $2.71(2.86)$ & $3.18(1.02)$ & & \\
\hline \multirow[t]{3}{*}{ VASL } & SMWLM (20) & $4.02(2.43)$ & $2.14(1.20)$ & $1.587(2.41)$ & $1.64(1.08-2.11)$ & 0.048 \\
\hline & PINS (20) & $4.01(1.89)$ & $2.88(2.13)$ & $1.33(3.64)$ & & \\
\hline & COMBINED (20) & $2.68(3.01)$ & $1.03(0.68)$ & $1.65(2.03)$ & & \\
\hline \multirow[t]{3}{*}{ VASB } & SMWLM (20) & $2.98(3.71)$ & $2.34(2.67)$ & $0.64(1.39)$ & $1.01(0.92-1.97)$ & 0.021 \\
\hline & PINS (20) & $3.97(2.62)$ & $3.68(1.59)$ & $0.31(1.80)$ & & \\
\hline & COMBINED (20) & $2.21(2.53)$ & $1.07(0.34)$ & $1.14(0.76)$ & & \\
\hline \multirow[t]{3}{*}{ SBI } & SMWLM (20) & $12.32(5.11)$ & $5.02(4.53)$ & $3.80(1.04)$ & $4.02(1.27-4.80)$ & 0.001 \\
\hline & PNS (20) & $13.01(4.69)$ & $9.63(6.49)$ & $1.38(3.17)$ & & \\
\hline & COMBINED (20) & $11.97(5.48)$ & $3.56(3.84)$ & $3.54(0.88)$ & & \\
\hline
\end{tabular}

RMDQ, Rolland-Morris Disability Questionnaire; SBI, Sciatica Bothersome Index; VASL, Visual Analog Scale for leg pain; VASB, Visual Analog Scale for back pain. 
Table 6: Six-month to nine-month follow-up change scores for clinical outcomes.

\begin{tabular}{|c|c|c|c|c|c|c|}
\hline Variable & Group (n) & $\begin{array}{r}\text { Six-month } \\
\text { follow-up } \\
\text { Mean (SD) }\end{array}$ & $\begin{array}{r}\text { Nine-month } \\
\text { follow-up } \\
\text { Mean (SD) }\end{array}$ & $\begin{array}{r}\text { Within-group } \\
\text { change score } \\
\text { Mean (SD) }\end{array}$ & $\begin{array}{r}\text { Between-group change } \\
\text { score mean }(95 \% \mathrm{Cl})\end{array}$ & p-value \\
\hline \multirow[t]{3}{*}{ RMDQ } & SMWLM (20) & $5.33(2.71)$ & $4.72(1.33)$ & $0.62(1.68)$ & $1.26(0.88-3.46)$ & 0.028 \\
\hline & PINS (20) & $6.00(4.01)$ & $5.68(4.22)$ & $0.32(2.03)$ & & \\
\hline & COMBINED (20) & $2.71(2.86)$ & $1.26(1.04)$ & $1.45(0.87)$ & & \\
\hline \multirow[t]{3}{*}{ VASL } & SMWLM (20) & $2.14(1.20)$ & $1.88(0.22)$ & $0.26(0.98)$ & $1.52(1.32-2.07)$ & 0.044 \\
\hline & PINS (20) & $2.88(2.13)$ & $2.67(1.69)$ & $0.21(0.41)$ & & \\
\hline & COMBINED (20) & $1.03(0.68)$ & $0.42(0.03)$ & $0.61(0.02)$ & & \\
\hline \multirow[t]{3}{*}{ VASB } & SMWLM (20) & $2.34(2.67)$ & $1.97(3.67)$ & $0.37(1.24)$ & $1.02(0.87-1.69)$ & 0.001 \\
\hline & PINS (20) & $3.68(1.59)$ & $2.31(2.54)$ & $1.37(0.98)$ & & \\
\hline & COMBINED (20) & $1.07(0.34)$ & $0.22(0.10)$ & $0.85(1.27)$ & & \\
\hline \multirow[t]{3}{*}{ SBI } & SMWLM (20) & $5.02(4.53)$ & $3.31(1.87)$ & $1.72(2.22)$ & $1.05(0.98-2.57)$ & 0.020 \\
\hline & PNS (20) & $9.63(6.49)$ & $7.98(2.77)$ & $1.64(3.34)$ & & \\
\hline & COMBINED (19) & $3.56(3.84)$ & $1.67(0.13)$ & $1.89(1.84)$ & & \\
\hline
\end{tabular}

RMDQ, Rolland-Morris Disability Questionnaire; SBI, Sciatica Bothersome Index; VASL, Visual Analog Scale for leg pain; VASB, Visual Analog Scale for back pain.

the two treatment techniques (SMWLM and PINS) and data were reported for long-term follow-ups.

Our findings also showed that there were significant between-group differences in all outcomes with the combined treatment group (SMWLM + PINS) having greater improvement in all outcomes (pain, disability, and sciatica bothersomeness) at all timelines than the individual treatment groups (SMWLM or PINS). Additionally, the SMWLM group showed better improvement than the PINS group. These findings are similar to those of Das et al. [22], Thakur et al. [31], and Yadav et al. [35], which reported better improvement in the SMWLM group than the comparison groups. In contrast to our current findings, a previous study by Ahmed et al. [34] reported better improvement in the comparison group than the SMWLM group. Another previous study [18] reported no betweengroup differences in all outcomes which further contrasted this current finding.

The significant improvement achieved in our study after administering a combined treatment approach may not be unrelated to the ability of the two treatment techniques in ameliorating nerve root compression and sciatica. First, SMWLM has been indicated to relieve nerve compression through increased intervertebral disc space gapping, nucleus deformation, and simultaneous approximation in the alternate layers of the annulus, thereby producing favorable therapeutic effects on the intervertebral disc [19]. While decreased diffusion of water and loss of proteoglycans are hallmarks of disc degeneration, it has been suggested that fluid exchange is integral to maintaining disc nutrition [36]. Mobilizations such as posterioranterior $(\mathrm{P}-\mathrm{A})$ glides have been reported to result in pain relief and improved motion in individuals with low back pain [37-39] while also improving disc hydration [40-42]. Given that SMWLM is a form of P-A gliding mobilization, it is conceivable that this technique could correct the positional fault by relieving pressure from the structures that compress the nerves, improving disc hydration, and also reducing the extent of pain via centralization [19].

On the other hand, PINS has been indicated to reduce lower limb radiating pain through increased hyperemia and washing away of the metabolites in the neuromuscular structures following myofascial trigger point deactivation [20]. Additionally, the ischemic compression applied on the sensitive neuromuscular structures using PINS may also elicit counterirritant effect in which large, fastconducting afferent fibers in the dorsal horn of the spinal cord and collateral fibers in the substantia gelatinosa or adjacent interneurons inhibit the transmission of pain via the spinothalamic tract [20]. In this manner, pressure acts as a stimulant to neighboring tissues, reducing the sensitivity of the original tender point and thus resolving pain [43]. Similar findings were also reported by a previous study [44] which indicated that sciatic nerve manipulation may promote healing of the soft tissues by stimulating the functions of the nervous system to improve nervous system adaptability and decrease sensitivity, helping to alleviate the symptoms. All these effects of SMWLM and PINS may be responsible for the better improvement achieved in the combined treatment group.

Moreover, in analyzing our data, it was observed that the participants' body mass indices (BMIs) ranged from the normal weight to overweight, with the combined 
treatment group having the highest mean BMI. Despite having a higher mean BMI, the combined treatment group showed better improvement (in all outcomes) than the individual manual therapy groups, indicating that this improvement may be attributed to the combined therapies (SMWLM + PINS) administered in this group. This finding corroborates with those of Vismara et al. [45], who reported greater improvement in biomechanical parameters of the thoracic spine in obese patients with chronic low back pain managed with osteopathic manipulative treatment (OMT) than those treated with specific exercises. Similar findings were also reported by Licciardone et al. [46], who indicated that the OMT effects for LBP intensity and back-specific functioning were independent of baseline patient demographic characteristics, comorbid medical conditions, and medication use.

Although therapeutic exercises were incorporated along with the manual therapy techniques in our study, we found that these exercises cannot be used as sole treatments for individuals suffering from lumbar radiculopathy secondary to disc herniation [47-49]. However, given the significance of a well-trained core in the for back stability, it is conceivable that these exercises may be used as adjunct therapies [50,51]. Additionally, it is also worthy of note that the long-term improvement achieved in our study may be attributed to the combined effects of both manual and exercise therapies.

\section{Limitations}

This study was limited to individuals with unilateral lumbar radiculopathy and data was collected in only one clinical setting. Additionally, this study did not also assess psychosocial variables that may be associated with chronic and persistent conditions like lumbar radiculopathy secondary to disc herniation. Further, it might have also been useful to use a 4th group as a control, which could have allowed us to monitor the natural evolution of the disease and pain. Future studies should be conducted to address these issues.

\section{Clinical relevance to osteopathic medicine}

Osteopathic manipulative treatment (OMT) is a set of handson techniques used by osteopathic physicians (DOs) to diagnose, treat, and prevent illness or injury. OMT is performed by a DO; while manipulative therapy in our study was not performed by a DO, similarities may be appreciated. Our study demonstrated the therapeutic efficacy of using PINS as an indirect OMT in the management of LDHR. The application of PINS involves the palpation of myofascial trigger points (TrPs) along a neuromuscular structure and then applying ischemic compression to progressively deactivate those TrPs. PINS technique is very similar to other indirect OMTs such as strain-counter strain (SCS) or positional release therapy (PRT), only TrPs are progressively deactivated along a neuromuscular continuum in the PINS technique. It is therefore recommended that osteopaths and other highly informed healthcare professionals may consider the use of PINS either as a sole or an complementary treatment in the management of patients with lumbar radiculopathy secondary to disc herniation.

\section{Conclusions}

Our results showed that combined SMWLM and PINS therapy along with a structured home exercise program was better than the individual techniques alone in the management of individuals with lumbar radiculopathy secondary to disc herniation.

Research funding: None declared.

Author contributions: Drs Bello, Yakasai, and Kaka and $\mathrm{Mr}$ Danazumi provided substantial contributions to conception and design, acquisition of data, or analysis and interpretation of data; Mr Danazumi drafted the article and revised it critically for important intellectual content; all authors gave final approval of the version of the article to be published; and all authors agree to be accountable for all aspects of the work in ensuring that questions related to the accuracy or integrity of any part of the work are appropriately investigated and resolved.

Competing interests: Authors state no conflict of interest. Informed consent: Written informed consent was obtained from the participants and they were assured of their rights to withdraw from the study at any point in time and their full anonymity was maintained.

Ethical approval: Ethical approval to conduct this study was obtained from the Health Research Ethics Committee of the Federal Medical Centre (FMC), Nguru, Yobe State, Nigeria (Registration number: FMC/N/CL.SERV/355/ VOL.IV/139). The trial was registered with the Pan African Clinical Trial Registry (PACTR201907782710996) on July 11, 2019.

\section{References}

1. Linqiu Z, Schneck CD, Shao Z. The anatomy of dorsal ramus nerves and its implications in lower back pain. Neurosci Med 2012;3: 192-201. 
2. Casey E. Natural history of radiculopathy. Phys Med Rehabil Clin 2011;22:1-5.

3. Valat JP, Genevay S, Marty M, Rozenberg S, Koes B. Sciatica. Best Pract Res Clin Rheumatol 2010;24:241-52.

4. Schoenfeld AJ, Weiner BK. Treatment of lumbar disk herniation: evidence based practice. Int J Med 2010;3:209-14.

5. Ostelo RW. Physiotherapy management of sciatica. J Physiother 2020;66:83-8.

6. Skelly AC, Chou R, Dettori JR, Turner JA, Friedly JL, Rundell SD, et al. Noninvasive nonpharmacological treatment for chronic pain: a systematic review update. Rockville (MD): Agency for Healthcare Research and Quality (US); 2020. Report No.: 20-EHC009. PMID: 32338846.

7. Maxwell CM, Lauchlan DT, Dall PM. The effects of spinal manipulative therapy on lower limb neurodynamic test outcomes in adults: a systematic review. J Man Manip Ther 2020;28:4-14.

8. Delitto A, George SZ, Van Dillen L, Whitman JM, Sowa G, Shekelle P, et al. Low back pain. J Orthop Sports Phys Ther 2012; 42:A1-57.

9. Danish Health Authority. National Clinical Guideline: interventions for recent onset lumbar radiculopathy [in Danish]; 2016. https:// www.sst.dk/da/udgivelser/2016/lumbal-nerverodspaavirkningikke-kirurgisk-behandling [Accessed 30 Oct 2020].

10. Stochkendahl MJ, Kjaer P, Hartvigsen J, Kongsted A, Aaboe J, Andersen $\mathrm{M}$, et al. National Clinical Guidelines for non-surgical treatment of patients with recent onset low back pain or lumbar radiculopathy. Eur Spine J 2018;27:60-75.

11. Hidalgo B, Detrembleur C, Hall T, Mahaudens P, Nielens H. The efficacy of manual therapy and exercise for different stages of non-specific low back pain: an update of systematic reviews. J Man Manip Ther 2013;22:59-74.

12. Slater SL, Ford JJ, Richards MC, Taylor NF, Surkitt LD, Hahne AJ. The effectiveness of sub-group specific manual therapy for low back pain: a systematic review. Man Ther 2012;17:201-12.

13. Clar C, Tsertsvadze A, Court R, Hundt GL, Clarke A, Sutcliffe P. Clinical effectiveness of manual therapy for the management of musculoskeletal and non-musculoskeletal conditions: systematic review and update of UK evidence report. Chiropr Man Ther 2014;22:12.

14. Swanson BT, Creighton D. The degenerative lumbar disc: not a disease, but still an important consideration for OMPT practice: a review of the history and science of discogenic instability. J Man Manip Ther 2020;28:191-200.

15. Berry JA, Elia C, Saini HS, Miulli DE. A review of lumbar radiculopathy, diagnosis, and treatment. Cureus 2019;11:e5934.

16. Dan-Azumi MS, Bello B, Rufai SA, Abdurrahman MA. Surgery versus conservative management for lumbar disc herniation with radiculopathy: a systematic review and meta-analysis. J Health Sci 2018;8:42-53.

17. Chen B, Guo J, Zhang H, Zhang YJ, Zhu Y, Zhang J, et al. Surgical versus non-operative treatment for lumbar disc herniation: $a$ systematic review and meta-analysis. Clin Rehabil 2018;32: 146-60.

18. Bello B, Danazumi MS, Kaka B. Comparative effectiveness of 2 manual therapy techniques in the management of lumbar radiculopathy: a randomized clinical trial. J Chiropr Med 2019;18: 253-60.

19. Mulligan BR. Update on spinal mobilisations with leg movement. J Man Manip Ther 1997;5:184-7.
20. Dowling DJ. Progressive inhibition of neuromuscular structures (PINS) technique. J Am Osteopath Assoc 2000;100:285-6.

21. Faul F, Erdfelder E, Buchner A, Lang AG. Statistical power analyses using $G *$ Power 3.1: tests for correlation and regression analyses. Behav Res Methods 2009;41:1149-60.

22. Das MSS, Dowle P, lyengar R. Effect of spinal mobilization with leg movement as an adjunct to neural mobilization and conventional therapy in patients with lumbar radiculopathy: randomized controlled trial. J Med Sci Clin Res 2018;6: 356-64.

23. Suresh KP, Chandrashekara S. Sample size estimation and power analysis for clinical research studies. J Hum Reprod Sci 2012;5: 7-13.

24. Rabin A, Gerszten PC, Karausky P, Bunker CH, Potter DM, Welch WC. The sensitivity of the seated straight-leg raise test compared with the supine straight-leg raise test in patients presenting with magnetic resonance imaging evidence of lumbar nerve root compression. Arch Phys Med Rehabil 2007;88:840-3.

25. Majlesi J, Togay H, Unalan H, Toprak S. The sensitivity and specificity of the Slump and the Straight Leg Raising tests in patients with lumbar disc herniation. J Clin Rheumatol 2008;14: 87-91.

26. Walsh J, Hall T. Agreement and correlation between the straight leg raise and slump tests in subjects with leg pain. J Manip Physiol Ther 2009;32:184-92.

27. Kamath SU, Kamath SS. Lasègue's sign. J Clin Diagn Res 2017;11: RG01-2.

28. Shi J, Jia L, Yuan W, Shi G, Ma B, Wang B, et al. Clinical classification of cauda equina syndrome for proper treatment. Acta Orthop 2010;81:391-5.

29. Yao M, Xu BP, Li ZJ, Zhu S, Tian ZR, Li DH, et al. A comparison between the low back pain scales for patients with lumbar disc herniation: validity, reliability, and responsiveness. Health Qual Life Outcome 2020;18:175.

30. Haugen AJ, Grøvle L, Brox JI, Natvig B, Keller A, Soldal D, et al. Estimates of success in patients with sciatica due to lumbar disc herniation depend upon outcome measure. Eur Spine J 2011;20: 1669-75.

31. Thakur A, Mahapatra RK, Mahapatra R. Effect of Mulligan spinal mobilization with leg movement and shacklock neural tissue mobilization in lumbar radiculopathy: a randomised controlled trial. J Med Thesis 2015;3:27-30.

32. Mulligan BR. Manual therapy: "NAGS," "SNAGS,", “MWMS” etc, 5th ed. Wellington, New Zealand: Plane View Services; 2004.

33. Streiner D, Geddes J. Intention to treat analysis in clinical trials when there are missing data. Evid Base Ment Health 2001;4:70-1.

34. Ahmed N, Khan Z, Chawla C. Comparison of Mulligan's spinal mobilisation with limb movement (SMWLM) and neural tissue mobilization for the treatment of lumbar disc herniation: a randomized clinical trial. J Nov Physiother 2016;6:304.

35. Yadav S, Arora Nijhawan M, Panda P. Effectiveness of spinal mobilization with leg movement (SMWLM) in patients with lumbar radiculopathy (L5/S1 nerve root) in lumbar disc herniation. Int J Physiother Res 2014;2:712-8.

36. Johannessen W, Vresilovic EJ, Wright AC, Elliott DM. Intervertebral disc mechanics are restored following cyclic loading and unloaded recovery. Ann Biomed Eng 2004;32:70-6.

37. Bezci SE, Nandy A, O'Connell GD. Effect of hydration on healthy intervertebral disk mechanical stiffness. J Biomech Eng 2015; 137:10. 
38. Goodsell M. Short-term effects of lumbar posteroanterior mobilization in individuals with low-back pain. J Manip Physiol Ther 2000;23:332-42.

39. Powers CM, Beneck GJ, Kulig K, Landel RF, Fredericson M. Effects of a single session of posterior-to-anterior spinal mobilization and press-up exercise on pain response and lumbar spine extension in people with nonspecific low back pain. Phys Ther 2008;88:485-93.

40. Beattie PF, Arnot CF, Donley JW, Noda H, Bailey L. The immediate reduction in low back pain intensity following lumbar joint mobilization and prone press-ups is associated with increased diffusion of water in the L5-S1 intervertebral disc. J Orthop Sports Phys Ther 2010;40:256-64.

41. Beattie PF, Donley JW, Arnot CF, Miller R. The change in the diffusion of water in normal and degenerative lumbar intervertebral discs following joint mobilization compared to prone lying. J Orthop Sports Phys Ther 2009;39:4-11.

42. Beattie PF, Morgan PS, Peters D. Diffusion-weighted magnetic resonance imaging of normal and degenerative lumbar intervertebral discs: a new method to potentially quantify the physiologic effect of physical therapy intervention. J Orthop Sports Phys Ther 2008;38:42-9.

43. Wong CK. Strain counterstrain: current concepts and clinical evidence. Man Ther 2012;17:2-8.

44. Jeong UC, Kim CY, Park YH, Hwang-Bo G, Nam CW. The effects of self-mobilization techniques for the sciatic nerves on physical functions and health of low back pain patients with lower limb radiating pain. J Phys Ther Sci 2016;28:46-50.
45. Vismara L, Cimolin V, Menegoni F, Zaina F, Galli M, Negrini S, et al. Osteopathic manipulative treatment in obese patients with chronic low back pain: a pilot study. Man Ther 2012;17: 451-5.

46. Licciardone JC, Gatchel RJ, Aryal S. Targeting patient subgroups with chronic low back pain for osteopathic manipulative treatment: responder analyses from a randomized controlled trial. J Am Osteopath Assoc 2016;116:156-68.

47. Kreiner DS, Hwang SW, Easa JE, Resnick DK, Baisden JL, Bess S, et al. North American Spine Society. An evidence-based clinical guideline for the diagnosis and treatment of lumbar disc herniation with radiculopathy. Spine J 2014;14:180-91.

48. Danazumi MS. Physiotherapy management of lumbar disc herniation with radiculopathy: a narrative review. Niger J Exp Clin Biosci 2019;7:93-100.

49. Alzubeidi SA, Alfawaz AA, Algharawi MY, Alrashidi AS, Alamrani MA, Alsayed AB. The effectiveness of stabilization exercises in treating patients with chronic low back pain: a systematic review. Asian J Orthop Res 2020;3:30-46.

50. Kriese M, Clijsen R, Taeymans J, Cabri J. Segmental stabilization in low back pain: a systematic review. Sportverletz Sportschaden 2010;24:17-25.

51. Ford JJ, Bower SE, Ford I, de Mello MM, Carneiro SR, Balasundaram AP, et al. Effects of specific muscle activation for low back pain on activity limitation, pain, work participation, or recurrence: a systematic review. Musculoskel Sci Pract 2020. https://doi.org/10.1016/j.msksp.2020. 102276. 